\title{
Max-Emanuel Geis
}

Friedrich-Alexander-Universität Erlangen-Nürnberg

max-emanuel.geis@fau.de

\section{Grundlagen und Entwicklungen der kommunalen Selbstverwaltung in Deutschland*}

\author{
Podstawy i rozwój samorządu gminnego w Niemczech
}

\section{ZUSAMMENFASSUNG}

Die kommunale Selbstverwaltung muss sich neuen Anforderungen an eine moderne Verwaltung stellen. Namentlich neue Formen der Privatisierung, etwa das sog. public private partnership erfordern Regelungsmodelle, die einerseits die Vorteile privaten Handelns nutzen können, ohne die rechtlich verbindlichen Kategorien aufzugeben, insb. das Prinzip der demokratischen Verantwortlichkeit. Desgleichen ist gerade die kommunale Haushaltswirtschaft auf eine betriebswirtschaftliche input-output-Analyse des Ressourceneinsatzen angewiesen. Hierzu werden derzeit in ganz Deutschland die herkömmlich kameralistische Rechnungsweise auf eine betriebswirtschaftliche doppelte Buchführung umgestellt (sog. Doppik).

Keywords: kommunale Selbstverwaltung, rechtliche Grundlagen, Selbstverwaltungsgarantie, Gemeindehoheiten

\section{GRUNDLAGEN}

\section{A. Historische Grundlagen}

Die kommunale Selbstverwaltung in Deutschland ist ohne einen kurzen Blick in die Geschichte nicht voll zu verstehen. Wenn ich gefragt würde, welche spezifischenFaktoren für diese Institution geprägt gewesen sind, würde ich drei Faktoren nennen:

Erstens die politische und wirtschaftliche Bedeutung der Städte im Mittelalter und in der frühen Neuzeit im Heilligen Römischen Reich deutscher Nation; sie

* Referat wygłoszony 24 maja 2013 r. na Międzynarodowej Konferencji Naukowej w Warszawie nt. Samorzad terytorialny w Polsce i w Niemczech. 
war das ökonomisches Rückgrat des Reiches. Auch wenn die Fürsten immer wieder versucht haben, die Macht der Städte zu brechen - etwa durch das Verbot von Städtebünden - konnten sie auf Dauer nicht verhindern, dass jedenfalls die von einer Patriziatsverfassung geprägten Freien Reichsstädte zur einem maßgeblichen Bestandteil eines Reichstags wurden. Die Macht der Kaiser wäre ohne die Finanzierung durch reiche städtische Kaufmannsgeschlechter nicht denkbar gewesen. Auch die Hanse, der ja auch polnische Städte wie Krakau und Breslau angehörten, zeigen diesen städtischen Sonderrang.

Zweitens das preußische Ideal der kommunalen Selbstverwaltung als Programm zum Wiederaufbau des Staates nach der katastrophalen Niederlage gegen Napoleon 1806. Die legendäre Städteordnung des Freiherrn von und zum Stein von 1808 setzt auf den Aufbau des Staates von „unten nach oben”, schuf eine Vertretung des Gemeindevolkes ohne Beschränkung auf ständische Vertreter und beabsichtigte eine durchgehende Erziehung der Bürger zum homo politicus. Dieses Modell war Vorbild für viele Gemeindeordnungen im 19. Jahrhundert.

Drittens war es eine ganz vergleichbare Situation nach dem Zweiten Weltkrieg. Die kommunale Selbstverwaltung war wieder Ausgangspunkt zum Wiederaufbau des Staates „,von unten nach oben”. Sie entsprach auch den Vorgaben der Allierten, die in diesem Element der Dezentralisierung eine Sicherung gegen gefährliche Machtkonzentrationen an der Staatsspitze sah. Dies erklärt Formulierungen wie etwa Art. 11 Abs. 2 der Bayerischen Verfassung: „Die Gemeinden sind ursprüngliche Gebietskörperschaften” als Hinweis auf die "soziologische” Vorstaatlichkeit.

\section{B. Rechtliche Grundlagen}

Zentrale Norm ist Art. 28 Abs. 2 GG als „Garantie der kommunalen Selbstverwaltung“. Doch auch die meisten Länderverfassungen, die zum Teil ja vor dem Grundgesetz in Kraft getreten sind, enthalten entsprechende Formulierungen.

Auf der gesetzlichen Ebene wird die kommunale Selbstverwaltung konkretisiert in den jeweiligen Gemeindeordnungen der Länder.

Grundgedanke ist: Die Gemeinden haben eigene Aufgaben und hierauf bezogene Befugnisse, einen ,eigenen Wirkungskreis”, in den der Staat nur durch Vorschriften oder Weisungen eingreifen darf, wenn die Gemeinde gegen Gesetze verstösst. Typischerweise gehören zu diesen Aufgaben die elementaren Bereiche der Daseinsvorsorge. Verfassungen und Gemeindeordnungen enthalten ausführliche Kataloge solcher Aufgaben. Paradebeispiel ist Art. 83 der Bayerischen Verfassung:

In den eigenen Wirkungskreis der Gemeinden (Art. 11 Abs. 2) fallen insbesondere die Verwaltung des Gemeindevermögens und der Gemeindebetriebe; der örtliche Verkehr nebst Straßen- und Wegebau; die Versorgung der Bevölkerung mit Wasser, Licht, Gas und elektrische Kraft; Einrich- 
tungen zur Sicherung der Ernährung; Ortsplanung, Wohnungsbau und Wohnungsaufsicht; örtliche Polizei, Feuerschutz; örtliche Kulturpflege; Volks- und Berufsschulwesen und Erwachsenenbildung; Vormundschaftsgewesen und Wohlfahrtspflege; örtliches Gesundheitswesen; Ehe- und Mütterberatung sowie Säuglingspflege; Schulhygiene und körperliche Ertüchtigung der Jugend; öffentliche Bäder; Totenbestattung; Erhaltung ortsgeschichtlicher Denkmäler und Bauten.

Selbstverwaltung geht regelmäßig mit einem bestimmten Organisationsmodell einher: Kollegiales Organ: Gemeinderat (Stadtrat) + monokratisches Organ: (Ober-)bürgermeister.

Bei zahlreichen Abweichungen in den Ländern - man unterscheidet eine norddeutsche, preußisch beeinflusste Tradition und eine süddeutsche Tradition kann man sagen: Für die grundsätzlichen Entscheidungen und für die Ortsrechtssetzung ist der Gemeinderat zuständig, für die laufenden Angelegenheiten und die Führung der Gemeindeverwaltung der Bürgermeister.

\section{Rechtliche Inhalte:}

Art. 28 Abs. 2 GG enthält zum einen eine institutionelle Rechtsgarantie: Es muss Gemeinden und Gemeindeverbände als Typus einer rechtsfähigen Gebietskörperschaft des öffentlichen Rechts geben. Jedoch lässt sich daraus kein Recht einer einzelnen Gemeinde ableiten, in ihrem Bestand unverändert zu bleiben; nicht einmal ein subjektives Recht auf fortdauernde Existenz (die Gebietsreform der 70er Jahren, die vielen Gemeinden zu größeren Gemeinden neugeordnet hat).

\section{Objektive Rechtsinstitutionsgarantie}

Art. 28 Abs. 2 GG garantiert die Vermutung der Allzuständigkeit der Gemeinden (nicht der Gemeindeverbände!) für die eigenverantwortliche Erledigung der Aufgaben im örtlichen Bereich. Der Staat kann nur überwachen, ob die Gemeinden sich im Rahmen der Gesetze halten; er kann aber keine inhaltlichen Weisungen geben. Wenn der Staat kommunale Aufgaben anderen Rechtsträger zuweist, bedarf er dazu eines rechtfertigenden Grundes - etwa die finanzielle Leistungsfähigkeit der Gemeinde.

\section{Subjektive Rechtsstellungsgarantie}

Das Selbstverwaltungsrecht ist ein subjektives Recht, das ähnlich wie ein Grundrecht konstruiert ist. Gemeinden können sich gegen Eingriffe des Staates in ihren eigenen Wirkungskreis vor Gericht wehren. Auf Bundesebene steht hierzu der eigene Rechtsbehelf der kommunalen Verfassungsbeschwerde (Art. 93 I Nr. 4b GG) zur Verfügung. Für die erwähnten Garantien der kommunalen Selbstverwaltung stellen einige Landesverfassungen spezielle Rechtsbehelfe zu den Landsverfassungsgerichten bereit (etwa Art. 76 Landesverfassung BW). In Bayern können die Kommunen auch Popularklage nach Art. 98 S. 4 der bayeri- 
schen Verfassung erheben. Darin setzt sich die allgemeine Erkenntnis durch, dass verfassungsrechtliche Garantien nur dann sinnvoll sind, wenn sie auch gerichtlich durchsetzbar sind.

Die Selbstverwaltungsgarantie äußerst sich v.a. in den sog.

\section{Sieben Gemeindehoheiten:}

\section{Zunächst die Gebietshoheit:}

Darunter versteht man die Rechtsmacht zum hoheitlichen Auftreten und rechtserheblichen Handeln gegenüber allen Personen und Sachen, die sich auf dem Gebiet der Gemeinde befindet.

Zweite Hoheit ist die Personalhoheit, also das Recht, eigenverantwortlich die kommunalen Beamten und Angestellten auszuwählen, zu ernennen, zu befördern und zu entlassen (beamtenrechtlich besitzt die Gemeinde also Dienstherreigenschaft, freilich auch zu bezahlen).

\section{Die Organisationshoheit}

Bezeichnet das Recht, die Binnenorganisation und Geschäftsverteilung in eigener Verantwortung zu regeln, Schaffung von Ämtern/Dezernaten (also beispielsweise Umweltdezernaten, Kulturreferenten, Migrationsbeauftragte, Tourismuschefs usw.).

\section{Satzungshoheit}

Ist die Kompetenz, eigenes Recht in allen Angelegenheiten des eigenen Wirkungskreises zu erlassen („Ortsrecht”), Art. 23 BayGO; in Art. 24 GO nicht abschließend geregelt. Diese Ermächtigung ist nicht wie bei Rechtsverordnungen vom Gesetzgeber streng in Inhalt, Zweck und Ausmaß zu begrenzen, sondern gilt innerhalb des Selbstverwaltungsbereichs umfassend.

Sonderfälle sind:

- Abgabesatzungen (Art. 2 BayKAG); Erschließungsbeitragssatzungen (§ 132 BauGB)

- Städtebauliche Satzungen (§ 142, § 154 Abs. 2a, § 172 BauGB), insb. Bebauungspläne

Ein vornehmes Recht ist die Planungshoheit.

Darunter versteht man das Recht zur eigenverantwortlichen Planung der örtlichen Entwicklung, insb. durch Aufstellung von Flächennutzungs- und Bebauungsplänen ( $(1 \mathrm{BauGB})$; allgemein das Recht auf gestalterische Stadtentwicklung oder das Recht auf das kommunale Erscheinungsbild. Bebauungspläne sind ebenfalls gemeindliche Satzungen, ihre Aufstellung folgt jedoch einem weite- 
gehenden Verfahrenach dem Bewqesetz buch nicht dem Verfahren gewöhnlicher Satzungen.

\section{$\underline{\text { Kulturhoheit }}$}

Die Kulturhoheit ist im Bundesstaat weitgehend den Bundesländern vorbehalten. Die Pflege der örtlichen Kultur obliegt dabei den Gemeinden als eigene Aufgaben, insb. Kulturgüter im Gemeindegebiet zu schaffen, zu pflegen und zu fördern (Beispiele sind die Errichtungen von Schulen, Volkshochschulen, Bibliotheken, Theatern, die Förderung von Kulturvereinen usw.)

Die örtliche Kulturverwaltung ist dabei regelmäßig dem Typus der leistenden Verwaltung zuzuordnen (Förderung durch die Errichtung und Unterhaltung öffentlicher kulturellen Einrichtung oder kulturelle Subventionen an private Kulturträger).

Die letzte Hoheit und letztlich die wichtigste, ist die -

\section{Finanz- und Abgabenhoheit}

Das ist das Recht auf eigenverantwortliche Einnahmen- und Ausgabenwirtschaft, die in einer Haushaltssatzung geregelt werden. Unter Abgabenhoheit versteht man das Recht, Abgabensatzungen zu erlassen und die Abgaben zu verwalten (Verwaltungshoheit) und die Erträge aus den Abgaben zu verwalten und zu vereinnahmen (sog. Ertragshoheit).

Eingriffe in die kommunale Selbstverwaltung sind nicht ausgeschlossen, sie müssen aber gerechtfertigt sein. Dies wird ähnlich wie ein Grundrecht geprüft. Zunächst ist also zu prüfen, ob eine Angelegenheit der örtlichen Gemeinschaft vorliegt. Ist das zu bejahen, ist zu untersuchen, ob der Kernbereich der Selbstverwaltung oder nur der Randbereich betroffen ist? Im ersten Fall ist ein Eingriff unzulässig. Im Randbereich ist ein Eingriff hingegen als Konkretisierung des Gesetzesvorbehaltes in Art. 28 Abs. 2 GG (,im Rahmen der Gesetze”) zulässig; er muss jedoch nach neuerer Auffassung wie ein Grundrechtseingriff verhältnismäßig sein, d.h. er muss einem legitimem Eingriffszweck dienen, und für dessen Erreichung geeignet, erforderlich und angemessen sein. ben]

[Leitentscheidung: BVerfGE 79,127 - Rastede: „Hochzonung” von Aufga-

\section{Neuere Entwicklungen:}

Die früher klare Anknüpfung an das Gemeindegebiet wird unklarer, da in Ballungs- und Verdichtungsräumen die Daseinsvorsorge nicht mehr klar auf die eigenen Gemeindemitglieder beschränkt werden kann. Die zunehmende Verzah- 
nung kommunaler Bereiche macht neue Formen der kommunalen Zusammenarbeit notwendig.

Die kommunale Selbstverwaltung muss sich neuen Anforderungen an eine moderne Verwaltung stellen. Namentlich neue Formen der Privatisierung, etwa das sog. public private partnership erfordern Regelungsmodelle, die einerseits die Vorteile privaten Handelns nutzen können, ohne die rechtlich verbindlichen Kategorien aufzugeben, insb. das Prinzip der demokratischen Verantwortlichkeit. Desgleichen ist gerade die kommunale Haushaltswirtschaft auf eine betriebswirtschaftliche input-output-Analyse des Ressourceneinsatzen angewiesen. Hierzu wird derzeit in ganz Deutschland die herkömmlich kameralistische Rechnungsweise auf eine betriebswirtschaftliche doppelte Buchführung umgestellt (sog. Doppik).

\section{STRESZCZENIE}

Samorząd gminny musi sprostać nowym wymaganiom w zakresie nowoczesnej administracji. Szczególnie nowe formy prywatyzacji, jak na przykład tzw. partnerstwo publiczno-prywatne, wymagają takich modeli regulacji, które potrafią wykorzystać zalety prywatnego postępowania bez rezygnacji z kategorii prawnie wiążących, w szczególności zasady odpowiedzialności demokratycznej. Również gminna gospodarka budżetowa powinna się zdawać na ekonomiczną analizę input-output wykorzystywania zasobów. W nawiązaniu do tego w całych Niemczech tradycyjna kameralistyczna metoda rachunkowości zastąpiona została ekonomiczną metodą podwójnej księgowości.

Słowa kluczowe: samorząd terytorialny, Republika Federalna Niemiec, funkcjonowanie samorządu terytorialnego, geneza samorządu terytorialnego 